\title{
Article \\ Physical Activity Behaviour in 50- to 74-Year-Olds: Differences between Employed and Retired Individuals
}

\author{
Karl Spiteri ${ }^{1, *} \mathbb{(}$, John Xerri de Caro ${ }^{2} \oplus$, Kathleen England ${ }^{3}$, Neville Calleja ${ }^{3}$, Lee Smith ${ }^{4} \oplus$, Kate Grafton ${ }^{5}$ \\ and David R. Broom ${ }^{1}$ \\ 1 Centre for Sport, Exercise and Life Sciences Coventry University, Coventry CV1 2DS, UK; \\ david.broom@coventry.ac.uk \\ 2 Faculty of Health Sciences, University of Malta, MSD 2080 Msida, Malta; john.xerri-decaro@um.edu.mt \\ 3 Department of Health Information and Research, Ministry for Health, PTA 1313 G'Mangia, Malta; \\ kathleen.england@gov.mt (K.E.); neville.calleja@gov.mt (N.C.) \\ 4 Cambridge Centre for Sport and Exercise Sciences, Anglia Ruskin University, Cambridge CB1 1PT, UK; \\ Lee.Smith@aru.ac.uk \\ 5 School of Health and Social Care, University of Lincoln, Lincoln LN6 7TS, UK; KGrafton@lincoln.ac.uk \\ * Correspondence: spiterik2@coventry.ac.uk
}

Citation: Spiteri, K.; Xerri de Caro, J.; England, K.; Calleja, N.; Smith, L.; Grafton, K.; Broom, D.R. Physical Activity Behaviour in 50- to 74-Year-Olds: Differences between Employed and Retired Individuals. J. Ageing Longev. 2021, 1, 11-23. https://doi.org/10.3390/jal1010003

Academic Editor: Yunhwan Lee

Received: 14 June 2021

Accepted: 10 August 2021

Published: 24 August 2021

Publisher's Note: MDPI stays neutral with regard to jurisdictional claims in published maps and institutional affiliations.

Copyright: (C) 2021 by the authors. Licensee MDPI, Basel, Switzerland. This article is an open access article distributed under the terms and conditions of the Creative Commons Attribution (CC BY) license (https:// creativecommons.org/licenses/by/ $4.0 /)$.
Abstract: (1) Objectives: The study aimed to examine data from Malta's Health Interview Survey (HIS) to assess differences between persons in employment and those retired, across different time periods. (2) Methods: A repeat cross-sectional design was adopted. Data that were collected over a period of 12 years included three cross-sectional HIS waves (2002, 2008 and 2014). Data were analysed cross-sectionally and longitudinally using multilevel analysis. (3) Results: In total, 4690 participants between the ages of 50 and 74 years provided data on physical activity (PA). A statistical difference was found between those employed and retired, with the latter undertaking less PA MET min per week in 2002 and 2008. There was no difference in 2014. When adjusting for covariates, people in employment carried out less PA MET min per week (OR-0.16--0.02) compared to retired individuals. Using multilevel modelling, this study shows that individual factors such BMI and long-standing illness are predictors of PA behaviour as opposed to time trends. (4) Conclusion: Retirement can increase PA measured in MET minutes per week. Individual factors such as BMI, long-standing health problems and self-rated health could be causing the higher levels seen in the employed population during the studied period.

Keywords: physical activity; public health; aging; retirement

\section{Introduction}

Participation in physical activity (PA) is beneficial for almost all facets of health in older adults. Regular and sustained PA behaviour in older adults has been associated with a reduction in the risk of cardiovascular disease, some cancers, type 2 diabetes and functional decline [1]. Not meeting PA recommendations in older age has serious health implications, including, for example, an increased risk of falls, dementia, and lower bone density [2-4]. Major life events such as the death of a spouse, a change in job status or a change in residence have been shown to impact the PA behaviour of individuals [5,6].

Retirement is a life event which is of interest because it is a social process which working individuals experience [7]. Globally, there is no standard age at which people retire from paid work. For this study, we defined retirement as receiving a retirement pension as it presented an exit from paid employment. Until 2008, in Malta, people receiving a retirement pension were unable to work in gainful employment. Transitioning from work to retirement can cause changes in lifestyle and is an opportunity whereby PA can be increased as new life adjustments are taking place $[8,9]$.

Research highlights that leisure time PA, walking and domestic activities increase after retirement, but transport and total PA behaviour decrease [10]. There is also a preference 
for the intensity of PA to be of light and moderate intensity [11]. There is inconclusive evidence as to whether changes in PA during and after this major life event are maintained. Longitudinal studies on retirement indicate an initial increase with subsequent declines or stabilization of PA behaviour thereafter [11]. Differences in reported findings are attributed to the aspect of PA domains being examined and sex differences. Socio-economic status (SES) has been identified to influence the transition into retirement in different ways. After retirement, people in a lower SES tend to engage in lower moderate and vigorous PA levels [12]. This was associated with increased reports of illness, disability, and chronic disease. There are a number of barriers and facilitators to PA in older adults which differ between those nearing retirement age and those who have retired [13]. Those nearing retirement were found to find difficulty in regulating their PA behaviour and were motivated by fitness goals. Individuals in retirement age were motivated by the social aspect of PA and lacked belief in their ability to be physically active.

Surveillance data for Malta identified just $28 \%$ of older adults aged 65 years or older achieve the recommended level of PA [14]. Every five years the Department of Health Information and Research (DHIR) in Malta conducts a Health Interview Survey (HIS), which collates data on employment status and health determinants together with PA. If employment status is associated with a change in PA behaviour it would be expected that PA behaviour between those in employment and those retired due to statutory age differs. Studies investigating changes with employment status [15-20] used longitudinal data which are currently not available in Malta. The aim of this study was to (a) use the data from the HIS to obtain information on how PA might have changed over time in older adults around the time of retirement age and (b) assess any differences in PA with employment status across different time points.

\section{Materials and Methods}

Applying a repeat cross-sectional study design, data were obtained from the published HIS in Malta for the years 2002, 2008 and 2014. Permission to carry out the study was obtained from the DHIR and ethical clearance from the Sheffield Hallam ethics committee, refence number ER5441966.

The HIS for each year studied contains data from around 4000 persons across all age groups representing an adequate random sample of the Maltese population. The estimated population during these years ranged from 405,000 to 420,000 inhabitants. The total sample size (16 years and older) of the HIS, from which the data were extracted ( $n=5510$ in 2002; $n=5500$ in 2008; $n=4086$ in 2014), was based on a stratified sample calculation carried out by the DHIR. Participants were randomly selected by computerized methods from a population register provided by the National Statistics Office. The selected participants were individuals aged 15 years and older. All data collected were anonymous, as no personal identifiers were collected. A recruitment letter was sent to potential participants by mail which was followed by a telephone call. Those who consented undertook a structured interview at their home.

Based on previous research on PA correlates [21] for the purpose of this study, the variables analysed were age, gender, employment status, education, body mass index (BMI), marital status, self-rated health, various chronic conditions, activity limitation due to health problems, smoking and PA. Employment status was measured in six categories: unemployed, boarded out, retired, gainfully employed, homemaker and other (Table A1). Employment status was based on the person's self-assessment [22]; no set of criteria was used to categorise participants as being retired. Data was collected on three different PA intensities (walking, moderate and vigorous intensity), duration per day and per week. Data on sedentary behaviour was not available and hence not analysed. Questions used were very similar to the International Physical Activity Questionnaire-Short form (IPAQ) [23]; however, the questionnaire psychometric properties in Maltese language had not yet been tested [24]. For the purposes of this study, data was taken from a stratified sample of the participant population that fell within the ages of 50 and 74 years. The 
statutory age of retirement in Malta for the years studied was between 61 and 64 years and it was decided to include the 10 years prior and following the retirement age. This age range is similar to inclusion criteria adopted by Baxter et al. [9].

\section{Data and Statistical Analysis}

Analysis of the data was carried out in a cross-sectional manner for each surveyed year by examining age as a continuous variable. Data was analysed longitudinally using multilevel analysis with repeated cross-sectional data [25-27]. The categorical variables of work status and education background were merged as the limited number of participants did not allow for statistical analysis. As the survey progressed, more detailed information was gleaned on educational level such as Bachelors, post-graduate diploma, masters, and $\mathrm{PhD}$ (Appendix A Table A1). These were grouped together under tertiary education. In the work domain, data in six categories were collected: (1) unemployed, (2) other, (3) retired, (4) gainfully employed, (5) domestic work and (6) boarded out. The six categories were group into four groups: (1) employed, (2) retired, (3) domestic and (4) unemployed + other (Appendix A Table A2). Chronic diseases were analysed by summing the total number of diseases recorded.

Data analysis for PA was carried out in accordance with the IPAQ guidelines since the data collected via the HIS questionnaire was similar $[23,28]$. Both questionnaires collect data on PA behaviour including walking, moderate, and vigorous intensity PA of more than 10-min bouts at a time and number of days per week. Using the same system as IPAQ ensured a standardized approach which allowed for comparison with other studies. Three categories of PA intensity were extracted: walking, moderate and vigorous intensity PA. Data on the different intensities and durations were processed into Metabolic Equivalents (MET) minutes per week as per IPAQ guidelines. When summed up, these three intensities provided the total MET minutes per week score that was suggestive of the overall PA. MET minutes per week of PA categories were determined as low, medium or high based on IPAQ classification [23].

PA categories were statistically analysed as categorical variables for within-year variation. MET values were assessed for normal distribution using the Kolmogorov-Smirnov test. Data which were not normally distributed were transformed using $\log _{10}(x+1)$ and rechecked for their distribution. When normal distribution was not obtained, nonparametric tests were used to analyse the data. Mean and standard deviation were presented for continuous variables. The Pearson correlation, Chi-square, ANOVA, or their non-parametric equivalents were used for the analysis between variables.

Multilevel analysis was used to model PA as a continuous variable. Predictors were included in the model based on theoretical knowledge. This analysis was used to consider the data longitudinally. Assumptions for homoscedasticity and linear relationship between variables were assessed visually using scatter plot diagrams. Individual attributes were considered as level 1 analysis (employment status, BMI, number of chronic diseases and educational level) and survey years as level 2 analysis. PA as a continuous variable was considered the dependent variable [29]. Within the multilevel analysis, only employment and retirement status were considered.

A Microsoft Excel@ spreadsheet was developed to store and analyses the data. IBM SPSSC (version 26) was used to complete the inferential statistical analysis. Statistical significance was accepted if $p<0.05$.

\section{Results}

The number of included participants for the three years was 4690. The proportion of males and females was $47 \%$ and $53 \%$, respectively. A higher proportion of retired individuals was present in 2002. The absence of any chronic disease was reported by $18 \%$ of the participants, whilst $10 \%$ reported more than five chronic diseases. The level of educational was higher in the 2014 survey. Table 1 provides a descriptive analysis of the variables collected and the significant differences between the survey years. 
Table 1. Demographics by year of survey for the total population.

\begin{tabular}{|c|c|c|c|c|}
\hline Demographic per Survey Year & $2002 n(\%)$ & $2008 n(\%)$ & $2014 n(\%)$ & $p$ Value \\
\hline \multicolumn{5}{|l|}{ Sex } \\
\hline Male & $682(46.2)$ & $654(46.9)$ & $859(47.5)$ & \multirow{2}{*}{0.76} \\
\hline Female & $795(53.8)$ & $741(53.1)$ & $951(52.5)$ & \\
\hline \multicolumn{5}{|l|}{ Employment status } \\
\hline Employed & $414(28)^{\mathrm{a}}$ & $421(30.1)^{\mathrm{a}}$ & $538(29.7)^{a}$ & \multirow{4}{*}{$<0.001$ * } \\
\hline Retired & $498(33.6)^{\mathrm{a}}$ & $369(26.4)^{b}$ & $544(30.1)^{\mathrm{a}, \mathrm{b}}$ & \\
\hline Other & $100(6.8)^{b}$ & $83(5.9)^{a, b}$ & $81(4.5)^{b}$ & \\
\hline Domestic & $462(31.2)^{a}$ & $489(34.9)^{b}$ & $646(35.7)^{b}$ & \\
\hline \multicolumn{5}{|l|}{ Marital status } \\
\hline Single & $174(11.9)^{\mathrm{a}}$ & $192(13.7)^{\mathrm{a}}$ & $243(13.4)^{\mathrm{a}}$ & \multirow{3}{*}{$<0.001$ * } \\
\hline Married & $1125(76.7)^{a}$ & $1048(75)^{\mathrm{a}}$ & $1263(69.8)^{b}$ & \\
\hline Widowed & $122(8.3)^{a, b}$ & $101(7.2)^{b}$ & $174(9.6)^{a}$ & \\
\hline Other & $46(3.1)^{\mathrm{a}}$ & $57(4.1)^{\mathrm{a}}$ & $130(7.2)^{b}$ & \\
\hline BMI (mean) & 28.1 & 28.0 & 28.3 & 0.31 \\
\hline \multicolumn{5}{|l|}{ BMI categories } \\
\hline Underweight & $143(10.4)^{\mathrm{a}}$ & $307(23.3)^{b}$ & $302(17.8)^{c}$ & \multirow{4}{*}{$<0.001$ * } \\
\hline Healthy weight & $394(28.6)^{a}$ & $294(17.8)^{b}$ & $395(23.3)^{b}$ & \\
\hline Overweight & $440(32)^{a}$ & $395(30)^{a}$ & $488(28.8)^{\mathrm{a}}$ & \\
\hline Obese & $399(29)^{a}$ & $320(24.3)^{b}$ & $510(30.1)^{a}$ & \\
\hline Non-smokers & $1220(82.7)^{a}$ & $1087(78)^{b}$ & $1433(79.5)^{a, b}$ & $<0.001$ * \\
\hline \multicolumn{5}{|l|}{ Self-rated health } \\
\hline Good & $818(55.3)^{\mathrm{a}}$ & $947(67.7)^{b}$ & $1250(69.7)^{b}$ & \multirow{3}{*}{$<0.001$ * } \\
\hline Fair & $590(67.7)^{a}$ & $397(28.4)^{b}$ & $479(26.7)^{b}$ & \\
\hline Bad & $71(69.7)^{b}$ & $55(3.9)^{\mathrm{a}}$ & $65(3.6)^{a}$ & \\
\hline \multicolumn{5}{|l|}{ Education } \\
\hline No school + special schools & $82(5.6)^{\mathrm{a}}$ & $30(2.1)^{b}$ & $13(0.7)^{\mathrm{c}}$ & \multirow{4}{*}{$<0.001$ * } \\
\hline Primary & $789(53.5) \mathrm{b}$ & $604(43.2)^{b}$ & $626(34.6)^{c}$ & \\
\hline Secondary & $519(35.2)^{c}$ & $647(46.2)^{b}$ & $1010(55.9)^{c}$ & \\
\hline Tertiary & $84(5.7)^{a}$ & $118(8.4)^{b}$ & $159(8.8)^{b}$ & \\
\hline Mean self-reported chronic illness & 3 & 2 & 2 & $<0.001$ * \\
\hline Long-standing illness (yes) & $553(37.6)^{a}$ & $686(49.5)^{b}$ & $911(50.4) b$ & $<0.001$ * \\
\hline Activity limitation (no) & $1324(89.5)^{a}$ & $949(67.8)^{b}$ & $1664(92)^{c}$ & $<0.001 *$ \\
\hline \multicolumn{5}{|l|}{ PA behaviour } \\
\hline Low & $803(54.3)^{\mathrm{a}}$ & $733(52.4)^{\mathrm{a}}$ & $910(50.3)^{a}$ & \multirow{3}{*}{$<0.001 *$} \\
\hline Moderate & $398(26.9)^{a}$ & $480(34.3)^{b}$ & $785(43.4)^{c}$ & \\
\hline High & $279(18.9)^{a}$ & $187(13.4)^{b}$ & $115(6.4)^{c}$ & \\
\hline PA total MET minutes per week (mean) & 1932 & 1169 & 943 & $<0.001$ * \\
\hline
\end{tabular}

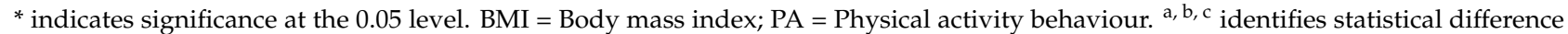
between columns.

In 2014, 6.4\% of the participants reported high PA behaviour, which is less when compared to 2008 (13.4\%) and 2002 (18.9\%). However, the number of people reporting moderate PA behaviour was greater in 2014 (43\%) compared to 2008 (34\%) and $2002(27 \%)$. Higher mean MET min per week scores were observed in 2002, and the lowest scores were observed in 2014. Based on ANOVA test with Dunnett's correction, the difference was statistically significant between years $(p<0.001)$. A higher variability in total MET min per week was obtained in 2002, and the lowest variability in total MET min per week was seen in 2014.

When comparing people in employment and those in retirement, there was a statistical difference in 2002 and 2008 but not 2014 (Table 2). What is noticeable is a decrease in the mean MET min per week in both groups. Employed individuals had statistically significant higher vigorous activity MET minutes per week then those in retirement in 2002 and 2008 (Table 3). In 2014, the mean vigorous activity MET minutes per week was still slightly higher in those in employment but the difference was not statistically significant $(p=0.36)$. 
Table 2. Interquartile ranges for total MET min per week employed vs. retired.

\begin{tabular}{|c|c|c|c|c|c|c|c|c|c|}
\hline \multicolumn{10}{|c|}{ Total MET min per Week } \\
\hline \multirow[t]{2}{*}{ Year } & \multicolumn{3}{|c|}{ Employed } & & & \multicolumn{3}{|c|}{ Retired } & \multirow[t]{2}{*}{$p$ Value } \\
\hline & $n$ & 25 th & 50th & 75 th & 25 th & $n$ & 50 th & 75 th & \\
\hline 2002 & 414 & 99 & 693 & 2966 & 99 & 498 & 693 & 2310 & $0.03 *$ \\
\hline 2008 & 421 & 132 & 693 & 1893 & 165 & 369 & 657 & 1386 & $<0.001 *$ \\
\hline 2014 & 538 & 264 & 660 & 1316 & 198 & 544 & 671 & 1320 & 0.86 \\
\hline
\end{tabular}

Table 3. Mean PA at different intensities comparing employed and retired individuals.

\begin{tabular}{|c|c|c|c|c|c|c|c|}
\hline Year & $\begin{array}{c}\text { Employment } \\
\text { Status }\end{array}$ & $\begin{array}{l}\text { Mean Total Walk } \\
\text { MET min per Week }\end{array}$ & $p$ Value & $\begin{array}{c}\text { Mean Total } \\
\text { Moderate MET } \\
\text { min per Week }\end{array}$ & $p$ Value & $\begin{array}{c}\text { Mean Total } \\
\text { Vigorous MET } \\
\text { min per Week }\end{array}$ & $p$ Value \\
\hline \multirow{2}{*}{2002} & Employed & 446 & \multirow{2}{*}{0.26} & 459 & \multirow{2}{*}{0.75} & 485 & \multirow{2}{*}{$<0.001$ * } \\
\hline & Retired & 465 & & 455 & & 432 & \\
\hline \multirow{2}{*}{2008} & Employed & 386 & \multirow{2}{*}{0.21} & 407 & \multirow{2}{*}{0.64} & 405 & \multirow{2}{*}{$0.02 *$} \\
\hline & Retired & 406 & & 382 & & 384 & \\
\hline \multirow{2}{*}{2014} & Employed & 539 & \multirow{2}{*}{0.75} & 547 & \multirow{2}{*}{0.36} & 544 & \multirow{2}{*}{0.36} \\
\hline & Retired & 544 & & 536 & & 539 & \\
\hline
\end{tabular}

* indicates significance at the 0.05 level.

Analysis of the IPAQ categories across the three surveys shows that $52.2 \%(n=2446)$ of the participants reported low PA behaviour and $12.4 \%(n=581)$ reported high PA behaviour. The findings in each PA category were similar for employed and retired persons (Table 4). The variables which were consistently significantly associated with total PA MET minutes per week across the three surveys were the presence of a long-standing illness, activity limitation, self-rated health, BMI and number of chronic conditions. Age, employment status and education were not always statistically related to PA categories (Table 5). Analysis with independent variable with walking, moderate and vigorous intensity PA as dependent variables are present in Appendix B.

Statistical modelling was carried out for the dependent variable of PA as a continuous variable. Total PA data were skewed, so data transformation was carried out to achieve data normalization. Initial model testing was carried out between total PA (dependent variable) and survey year as a second-level model [29]. The intercept within the model was not statistically significant $(p=0.364)$. The interclass correlation co-efficient for the level-2 model was 0.006 . Testing with level 1 (individual data) was included in the model. The model intercept of level-1 data was statistically significant $(p<0.001)$. Data are presented in Table 6.

Table 4. Physical activity IPAQ categories with employment status.

\begin{tabular}{ccccc}
\hline Year & PA Category & Employed $n(\%)$ & Retired $n(\%)$ & $p$ Value \\
\hline \multirow{2}{*}{2002} & Low & $213(51.4)^{\mathrm{a}}$ & $254(51)^{\mathrm{a}}$ & \\
& Moderate & $109(26.3)^{\mathrm{a}}$ & $147(29.5)^{\mathrm{a}}$ & 0.44 \\
& High & $92(22.2)^{\mathrm{a}}$ & $97(19.5)^{\mathrm{a}}$ & \\
\multirow{2}{*}{2008} & Low & $207(49.2)^{\mathrm{a}}$ & $183(49.6)^{\mathrm{a}}$ & \\
& Moderate & $141(26.3)^{\mathrm{a}}$ & $139(37.7)^{\mathrm{a}}$ & $0.025^{*}$ \\
& High & $73(17.3)^{\mathrm{a}}$ & $47(12.7)^{\mathrm{b}}$ & \\
& Low & $271(50.4)^{\mathrm{a}}$ & $263(48.3)^{\mathrm{a}}$ & \\
& Moderate & $227(42.2)^{\mathrm{a}}$ & $240(44.1)^{\mathrm{a}}$ & 0.79 \\
& High & $40(7.4)^{\mathrm{a}}$ & $41(7.5)^{\mathrm{a}}$ & \\
\hline
\end{tabular}

* indicates significance at the 0.05 level; $^{\text {a, }}{ }^{b}$ identifies statistical difference between columns. 
Table 5. Total MET min per week and independent variables.

\begin{tabular}{|c|c|c|c|}
\hline Variable & $2002(n=912)$ & $2008(n=790)$ & $2014(n=1082)$ \\
\hline Activity limitation & $-5.796^{* *}$ & $-2.611^{* *}$ & $-4.972 * *$ \\
\hline $\begin{array}{l}\text { Long-standing health } \\
\text { problems }\end{array}$ & $-5.539^{* *}$ & $-2.773 * *$ & $-7.065^{* *}$ \\
\hline Smoking & -0.508 & -0.523 & -1.678 \\
\hline Sex (male) & $-3.334^{* *}$ & $-2.869 *$ & -0.441 \\
\hline Self-rated health & $<0.001^{* *}$ & $<0.001 * *$ & $<0.001^{* *}$ \\
\hline Education & 0.014 & $<0.001^{* *}$ & 0.010 * \\
\hline Employment & 0.181 & $0.004 *$ & 0.832 \\
\hline Chronic conditions ${ }^{+}$ & $-0.104^{* *}$ & $-0.106^{* *}$ & $-0.136^{* *}$ \\
\hline $\operatorname{BMI}\left(\mathrm{kg} / \mathrm{m}^{2}\right)^{+}$ & $-0.111^{* *}$ & $-0.097^{* *}$ & $-0.161^{* *}$ \\
\hline Age (years) ${ }^{+}$ & -0.043 & $-0.093^{* *}$ & -0.043 \\
\hline
\end{tabular}

Mann-Whitney $\mathrm{U}$ test used the $\mathrm{Z}$ score. ${ }^{\sim}$ Kruskal-Wallis $\mathrm{H}$ test used the $p$ value. ${ }^{+}$Spearman correlation used the correlation co-efficient $r$. ${ }^{*}$ indicates significance at the 0.05 level. ${ }^{* *}$ indicates significance at the 0.01 level.

Table 6. Multilevel analysis includes level 1 (individual) and level 2 (survey year).

\begin{tabular}{|c|c|c|c|c|c|}
\hline & $\begin{array}{c}\text { Level } 1 \\
\text { Variable }\end{array}$ & Std Error & $\mathbf{t}$ & $95 \%$ CI & $p$ Value \\
\hline \multirow[b]{2}{*}{$\begin{array}{l}\text { Employment } \\
\text { status }\end{array}$} & Intercept & 0.45 & 14.81 & $2.21-4.03$ & $<0.001$ \\
\hline & $\begin{array}{l}\text { Employed } \\
\text { Retired }\end{array}$ & 0.334 & -2.67 & $-0.16--0.02$ & $0.007^{*}$ \\
\hline \multirow[t]{3}{*}{ Sex } & $\begin{array}{l}\text { Male } \\
\text { Female }\end{array}$ & 0.03 & 2.35 & $0.01-0.11$ & 0.19 \\
\hline & BMI & 0.02 & -4.11 & $\begin{array}{l}-0.01- \\
-0.004\end{array}$ & $<0.001^{* *}$ \\
\hline & Age & 0.002 & -2.35 & $\begin{array}{l}-0.01- \\
-0.001\end{array}$ & $0.03 *$ \\
\hline \multirow{5}{*}{ Marital Status } & Single & 0.06 & -1.19 & $-0.18-0.04$ & 0.25 \\
\hline & Married & 0.05 & -1.12 & $-0.15-0.04$ & 0.27 \\
\hline & $\begin{array}{l}\text { Widowed } \\
\text { Divorced }\end{array}$ & 0.06 & -0.78 & $-0.17-0.08$ & 0.43 \\
\hline & Very good & 0.14 & 2.51 & $0.07-0.63$ & $0.02 *$ \\
\hline & Good & 0.14 & 1.70 & $-0.04-0.51$ & 0.09 \\
\hline \multirow{3}{*}{ Self-Rate health } & Fair & 0.14 & 0.449 & $-0.02-0.34$ & 0.63 \\
\hline & Bad & 0.16 & -0.083 & $-0.43-0.17$ & 0.41 \\
\hline & Very Bad & & & & \\
\hline \multirow[t]{4}{*}{ Education } & No school & 0.12 & 0.29 & $-0.66-0.90$ & 0.77 \\
\hline & Primary & 0.14 & 0.35 & $-0.63-0.90$ & 0.72 \\
\hline & Secondary & 0.12 & 0.31 & $-0.63-0.88$ & 0.75 \\
\hline & $\begin{array}{l}\text { Tertiary } \\
\text { Special } \\
\text { schools }\end{array}$ & 0.15 & 0.37 & $-0.62-0.91$ & 0.71 \\
\hline \multirow{3}{*}{$\begin{array}{l}\text { Longstanding } \\
\text { health problem }\end{array}$} & Yes & -0.05 & -1.99 & $\begin{array}{l}-0.09 \\
-0.001\end{array}$ & $0.04 *$ \\
\hline & $\begin{array}{l}\text { No } \\
\text { Level } 2 \\
\text { Variable }\end{array}$ & & & & \\
\hline & Survey year & 0.004 & & $\begin{array}{l}-0.0004- \\
0.032\end{array}$ & 0.363 \\
\hline
\end{tabular}

\section{Discussion}

The aim of this study was to assess differences in PA behaviour between people retired due to old age and those in employment. Data from three cross-sectional surveys in Malta were used. In the studied population throughout the years, there was an increase in the proportion of people participating in moderate PA behaviour and a decrease in high PA behaviour, which was found to be statistically significant. The proportion of people who 
had a low level of PA behaviour remained not significantly different throughout the years. Consistent with trends reported in other countries such as Australia and the USA [30], a higher proportion of people within the total population reached moderate PA behaviour in each of the survey years.

When considering the total sample across the years, there was a decrease in the mean total MET minute per week which could be attributed to less people reaching high PA behaviour. There are less people who have high PA behaviour and more who have moderate PA behaviour. Statistical differences found when measuring PA categorially or in MET minutes per week were not congruent. IPAQ categories are based on a mix of days per week, duration and MET minutes per week, whilst continuous PA scores are in MET minutes per week; therefore, both parameters measure different aspects of PA behaviour.

There was a difference in the PA behaviour between retired and employed in the years of 2002 and 2008, when measured using MET minutes per week. This difference was only present in 2008 when grouping PA behaviour according to IPAQ categories. The difference in MET minutes per week is attributed to the amount of vigorous PA carried out by employed individuals which was significantly higher than those who retired for 2002 and 2008. Results indicate that there was a decrease in PA intensity in retired individuals, a difference that was not present in 2014. Studies found that there is a gradual decrease in the amount of vigorous PA, starting at the age of 40 years which continues to decrease in old-age retirees, even when adjusting for covariates (BMI, SES, limiting long-standing illness) [31,32]. The percentage of employed individuals reaching high levels of PA behaviour decreased by $14.8 \%$ from 2002 to 2014 in our data.

During the 12 years, the difference in MET minutes per week between retired and employed decreased, and any future data will be able to indicate whether there is a trend with retired individuals becoming more physically active than those in employment. However, these differences were not present when PA behaviour was analysed using IPAQ PA categories. A higher proportion of the retired individuals attained moderate PA behaviour compared to those employed. Leisure time PA activity has been shown to increase after retirement, which might be of vigorous or moderate intensity [10]. Similarly, our results indicate that there is a shift in the intensity level.

Leisure time PA tends to be higher in people with higher SES [31]. Education was used as a proxy for SES. The education levels in the studied cohorts increased with the surveyed years. This study found no correlation between education and PA intensities. A possible explanation is that SES is a non-static construct, and cross-sectional education might not ascertain these differences [33].

There was a trend for people in retirement to undertake more walking behaviour measured in MET min per week when compared to those in employment, but this did not reach statistical significance. Other studies have found a significant increase in walking activity after retirement $[31,34,35]$. These studies followed people across their retirement and looked at individual difference in PA behaviour. Malta exhibits a car culture with $80 \%$ of the population using a car to commute, even for the shortest distances with trips that could be walked in $10 \mathrm{~min}$ [36]. This might explain why no statistical difference was found between those employed and unemployed for car use, being high across all age groups.

In analysing the data on total MET minutes per week, for employed and retired people, longitudinally using multilevel modelling and considering survey years as a 2nd-level analysis, the data were found not to be statistically significant. One possible reason for this is the skewness in PA behaviour which required data transformation. In using data transformation, this could have influenced the statistical relationship [37]. Individual level (1st level) factors, i.e., being retired, male, low BMI, young age and good self-rate health, were found to predict PA behaviour. However, these predictors were not strong in explaining PA behaviour. This could mean that there are other variables, such as food intake and sleep, for which data were not collected but can predict PA behaviour better and should be measured in future studies. 
Similar to other studies [38], when examining PA behaviour with age this was only found to predict PA behaviour in the multilevel model. Having a long-standing health problem was associated with PA behaviour in all three survey years and within the model. In all three surveys a long-standing health problem was the most significantly associated factor with total MET. The presence of a long-standing health problem was related to the presence of activity limitation and self-rated health. These covariates might influence PA behaviour differently due to the interaction between these different factors when including them all together within the multilevel model, which would cause interaction between the variables as they measure conjoint factors. In old age, self-rated health is influenced by a person's outlook with respect to any concurrent abilities, whilst activity limitation is dependent on the person's physical abilities [39]. Self-rated health can influence the type of PA behaviour undertaken, as it reflects a person's outlook of self-ability $[40,41]$. However, given that the study age range was fixed throughout the three surveys, the correlation between age and PA behaviour could have been influenced.

Any increase in PA after retirement is believed to be short lived, and a decrease in PA is expected thereafter [11]. This study indicates that there are other important factors which influence PA behaviour when retired. Retirement is a process with no universally accepted start date $[42,43]$. Taking a resource-based dynamic process towards retirement explains why other variables such as history of PA and self-efficacy might be more important predictors of PA post-retirement rather than employment status. Retirement adjustment is influenced by the person's resources [43] and differences might not be present when analysing data at a population level.

\subsection{Limitations and Strengths}

This study is based on the analysis of secondary data, and therefore the data were not specifically collected for the study purpose, which creates limitations of result generalization specific to the effect of retirement [44]. One of the major limitations of the study is the inability to follow participants over time, due to the anonymous nature of the primary data collection. However, the sample size was large enough to be representative of the Maltese population.

The measurement of PA was completed using an in-house questionnaire, so its psychometric properties cannot be ascertained. However, it was similar to the IPAQ short form which has been deemed to be valid and reliable. Measurement of sedentary behaviour would have provided useful data for analysis and should be included in future iterations of the survey. Using questions similar to IPAQ in the older population might not be the most appropriate tool as there are other tools which are more specific to older adults [45]. Using MET minutes per week is a measure of absolute physiological intensity whilst self-reported measures measure relative intensity, which creates a discrepancy within the measurement [46]. This discrepancy occurred across all the populations under study.

The clear strength of this study is that to the authors' knowledge it is the first attempt to identify the possible effect of retirement on PA in the Maltese population. The study was able to distinguish between those in retirement and still employed. The recruited participant sample was representative of the population. The sample was able to assess cross-sectional changes across the 12 years under study. The analysis of PA was based on IPAQ guidelines, an international approved system with frequent use within the literature. This made it possible to analyse PA data in a continuous and categorical format [47].

\subsection{Future Research}

Given the limitations of secondary analysis, the relationship between PA and retirement should be examined further. Exploring the possible change in PA and its causes during retirement can help support national policy development to support PA promotion during the retirement transition. Future research should use a longitudinal design, measure PA, follow the same participants over time and explore how the experience of retirement might influence PA later in life using qualitative means. 


\subsection{Practical Implications}

The PA behaviour within the population decreased over time due to fewer people reaching vigorous PA behaviour. PA behaviours are expected to decrease with age, so promoting PA levels during retirement may have a beneficial influence on the health of the population [8]. Being in retirement was found to predict positive PA behaviours. An exploration of how retirement can have a beneficial influence on PA behaviour is warranted as well as interventions to encourage more vigorous PA behaviour.

\section{Conclusions}

This study investigated employment status and PA behaviour at a population and individual level by looking at the data longitudinally using a repeat cross-sectional design. Across the 12 years, based on the statistical model, people in retirement were more active than those in employment. Other factors such as BMI, long-standing health problems, age and self-rated health could be causing the higher levels seen in the employed population during the studied years. Irrespective of these variables, the study found that PA behaviour was similar between retired and employed persons in 2014. The levels of PA may be increasing among the retired population compared to those in employment, and analysis of future data set could be used to indicate whether this is a one-time cohort effect or a developing period trend.

Author Contributions: Conceptualization, K.S., K.G. and D.R.B.; validation, D.R.B., J.X.d.C. and L.S.; formal analysis, L.S.; investigation, K.E. and N.C.; resources, N.C. and K.E.; data curation, K.E.; writing-original draft preparation, K.S. and D.R.B.; writing—review and editing, J.X.d.C., K.E., N.C., L.S., K.G. and D.R.B.; visualization, K.S.; supervision, D.R.B.; project administration, K.E. and N.C.; funding acquisition, K.S. All authors have read and agreed to the published version of the manuscript.

Funding: This research was funded by ENDEAVOUR scholarship scheme-Group B—National funds-Malta, grant number MEDE/1117/2017/43.

Institutional Review Board Statement: The study was conducted according to the guidelines of the Declaration of Helsinki, and approved by the Sheffield Hallam University Research Ethic committee reference number: ER5441966 on 13/12/2017.

Informed Consent Statement: Participant consent was waived due to the study being a secondary data analysis of an anonymous dataset.

Data Availability Statement: Data can be made available by request to the Directorate for health information and research, Ministry for Health, Malta. https://deputyprimeminister.gov.mt/en/ dhir/Pages/Introduction.aspx (accessed on 2 August 2021).

Acknowledgments: We would like to thank the Directorate for Health Information and Research for providing us with the data for this study.

Conflicts of Interest: The authors declare no conflict of interest. The funders had no role in the design of the study; in the collection, analyses, or interpretation of data; in the writing of the manuscript, or in the decision to publish the results.

\section{Appendix A}

The Health interview survey collated data on education into seven different categories: no formal education, primary, lower secondary, upper secondary, post-secondary, tertiary first stage, tertiary second stage. The categories were grouped into five groups: no formal education, primary, secondary, and tertiary (Table A1). Work status was grouped into three categories: unemployed, which included boarded-out and permanent disability, domestic work, pensioners or retired and employed (Table A2). 
Table A1. Transformation of education categories.

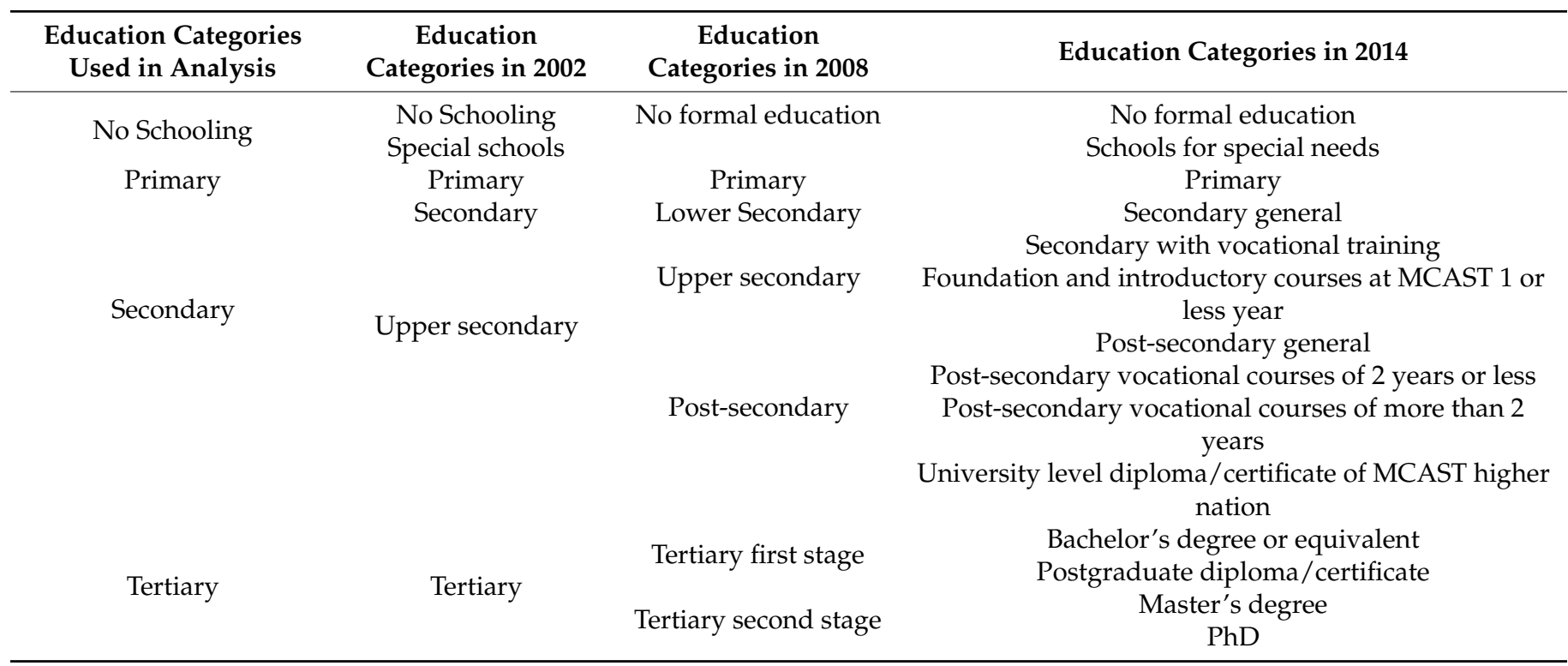

Table A2. Transformation of work categories.

\begin{tabular}{cccc}
\hline $\begin{array}{c}\text { Work Categories Used in } \\
\text { Analysis }\end{array}$ & Work Categories in 2002 & Work Categories in 2008 & Work Categories in 2014 \\
\hline & Unemployed & Unemployed & Unemployed \\
Unemployed + other & Other & Other & Other inactive person \\
& Poarded out & Permanent disability & Permanent disability \\
Retired & Retirement / given up & In retirement \\
Employed & Gainfully employed & Working for pay or profit & Working for pay or profit \\
Domestic & Homemaker & Domestic work & Fulfilling domestic tasks \\
\hline
\end{tabular}

\section{Appendix B}

Table A3. Walking MET min per week and independent variables.

\begin{tabular}{|c|c|c|c|}
\hline Variable & $2002(n)$ & $2008(n)$ & $2014(n)$ \\
\hline Activity limitation & $-4.846^{* *}$ & -1.635 & $-4.854^{* *}$ \\
\hline $\begin{array}{l}\text { Long standing health } \\
\text { problems }\end{array}$ & $-3.3733^{* *}$ & -0.308 & $-7.289 * *$ \\
\hline Smoking & -0.556 & -1.372 & -1.351 \\
\hline Sex (male) & -0.55 & -0.555 & -0.262 \\
\hline Self-rated health & $<0.001^{* *}$ & $<0.001^{* *}$ & $<0.001 * *$ \\
\hline Education & 0.827 & $0.016^{*}$ & 0.272 \\
\hline Employment & 0.134 & 0.317 & 0.981 \\
\hline Chronic conditions ${ }^{+}$ & $-0.079 * *$ & -0.35 & $-0.12 * *$ \\
\hline $\operatorname{BMI}\left(\mathrm{kg} / \mathrm{m}^{2}\right)^{+}$ & $-0.106^{* *}$ & $-0.077^{*}$ & $-0.135^{* *}$ \\
\hline Age (years) ${ }^{+}$ & -0.012 & -0.023 & -0.28 \\
\hline
\end{tabular}

Mann-Whitney U test used Z score. $\sim$ Kruskal-Wallis $\mathrm{H}$ test used $p$ value. ${ }^{+}$Spearman Correlation used correlation co-efficient $\mathrm{r} .{ }^{*}$ indicates significance at 0.05 level. ${ }^{* *}$ indicates significance at 0.01 level. 
Table A4. Moderate MET min per week and independent variables.

\begin{tabular}{|c|c|c|c|}
\hline Variable & $2002(n)$ & $2008(n)$ & $2014(n)$ \\
\hline Activity limitation & $-3.457 *$ & -1.791 & $-2.288^{*}$ \\
\hline $\begin{array}{l}\text { Long standing health } \\
\text { problems }\end{array}$ & $-3.347^{* *}$ & $-3.751^{* *}$ & $-2.983 *$ \\
\hline Smoking & -0.767 & -0.071 & -1.465 \\
\hline Sex (male) & $-2.852 *$ & -1.285 & $-2.055^{*}$ \\
\hline Self-rated health & $<0.001 * *$ & $<0.001^{* *}$ & $<0.001^{* *}$ \\
\hline Education & $<0.001^{* *}$ & $0.002 *$ & $<0.001 * *$ \\
\hline Employment & 0.306 & 0.010 * & 0.053 \\
\hline Chronic conditions $^{+}$ & -0.025 & $-0.105^{* *}$ & $-0.088^{*}$ \\
\hline $\operatorname{BMI}\left(\mathrm{kg} / \mathrm{m}^{2}\right)^{+}$ & $-0.083 *$ & -0.053 & $-0.123^{* *}$ \\
\hline Age (years) ${ }^{+}$ & -0.008 & -0.084 * & $-0.051 *$ \\
\hline
\end{tabular}

Mann-Whitney $\mathrm{U}$ test used $\mathrm{Z}$ score. $\sim$ Kruskal-Wallis $\mathrm{H}$ test used $p$ value. ${ }^{+}$Spearman Correlation used correlation co-efficient $\mathrm{r} .{ }^{*}$ indicates significance at 0.05 level. ${ }^{* *}$ indicates significance at 0.01 level.

Table A5. Vigorous MET min per week and independent variables.

\begin{tabular}{|c|c|c|c|}
\hline Variable & $2002(n)$ & $2008(n)$ & $2014(n)$ \\
\hline Activity limitation & $-2.242 *$ & -0.167 & -0.178 \\
\hline $\begin{array}{l}\text { Long standing health } \\
\text { problems }\end{array}$ & $-4.4116^{* *}$ & $-3.067 *$ & -0.729 \\
\hline Smoking & -1.355 & -0.034 & -1.651 \\
\hline Sex (male) ${ }^{\wedge}$ & $-3.285 *$ & -1.424 & -0.236 \\
\hline Self-rated health & $<0.001^{* *}$ & $<0.001^{* *}$ & $<0.001 * *$ \\
\hline Education & $0.005 *$ & 0.229 & $0.008 *$ \\
\hline Employment & $<0.001^{* *}$ & 0.063 & 0.833 \\
\hline Chronic conditions ${ }^{+}$ & $-0.084^{* *}$ & $-0.072^{* *}$ & -0.22 \\
\hline $\operatorname{BMI}\left(\mathrm{kg} / \mathrm{m}^{2}\right)^{+}$ & -0.045 & -0.046 & $-0.071^{* *}$ \\
\hline Age (years) ${ }^{+}$ & $-128^{* *}$ & $-0.78^{* *}$ & $-0.49 *$ \\
\hline
\end{tabular}

Mann-Whitney U test used Z score. $\sim$ Kruskal-Wallis $\mathrm{H}$ test used $p$ value. ${ }^{+}$Spearman Correlation used correlation co-efficient $\mathrm{r} .{ }^{*}$ indicates significance at 0.05 level. ${ }^{* *}$ indicates significance at 0.01 level.

\section{References}

1. UK Chief Medical Officers. UK Chief Medical Officers' Physical Activity Guidelines; UK Chief Medical Officers: London, UK, 2019.

2. Vogel, T.; Brechat, P.H.; Leprêtre, P.M.; Kaltenbach, G.; Berthel, M.; Lonsdorfer, J. Health benefits of physical activity in older patients: A review. Int. J. Clin. Pract. 2009, 63, 303-320. [CrossRef]

3. Kohl, H.W., 3rd; Craig, C.L.; Lambert, E.V.; Inoue, S.; Alkandari, J.R.; Leetongin, G.; Kahlmeier, S.; Lancet Physical Activity Series Working Group. The pandemic of physical inactivity: Global action for public health. Lancet 2012, 380, 294-305. [CrossRef]

4. Reiner, M.; Niermann, C.; Jekauc, D.; Woll, A. Long-term health benefits of physical activity—A systematic review of longitudinal studies. BMC Public Health 2013, 13, 813. [CrossRef]

5. Richards, E.A.; Thomas, P.A.; Forster, A.K.; Hass, Z. A Longitudinal Examination of the Impact of Major Life Events on Physical Activity. Health Educ. Behav. 2019, 46, 398-405. [CrossRef] [PubMed]

6. Koeneman, M.A.; Chinapaw, M.J.; Verheijden, M.W.; van Tilburg, T.G.; Visser, M.; Deeg, D.J.; Hopman-Rock, M. Do major life events influence physical activity among older adults: The Longitudinal Aging Study Amsterdam. Int. J. Behav. Nutr. Phys. Act. 2012, 9, 147. [CrossRef]

7. Ekerdt, D.J. Frontiers of research on work and retirement. J. Gerontol. B Psychol. Sci. Soc. Sci. 2010, 65B, 69-80. [CrossRef]

8. Barnett, I.; van Sluijs, E.; Ogilvie, D.; Wareham, N.J. Changes in household, transport and recreational physical activity and television viewing time across the transition to retirement: Longitudinal evidence from the EPIC-Norfolk cohort. J. Epidemiol. Community Health 2014, 68, 747. [CrossRef]

9. Baxter, S.; Blank, L.; Johnson, M.; Everson-Hock, E.; Woods, H.B.; Goyder, E.; Payne, N.; Mountain, G. Interventions to promote or maintain physical activity during and after the transition to retirement: An evidence synthesis. Public Health Res. 2016, 4, 1-138. [CrossRef]

10. Barnett, I.; van Sluijs, E.M.F.; Ogilvie, D. Physical activity and transitioning to retirement: A systematic review. Am. J. Prev Med. 2012, 43, 329-336. [CrossRef]

11. Gropper, H.; John, J.M.; Sudeck, G.; Thiel, A. The impact of life events and transitions on physical activity: A scoping review. PLoS ONE 2020, 15, e0234794. [CrossRef] 
12. Jones, S.A.; Li, Q.; Aiello, A.E.; O’Rand, A.M.; Evenson, K.R. Physical Activity, Sedentary Behavior, and Retirement: The Multi-Ethnic Study of Atherosclerosis. Am. J. Prev. Med. 2018, 54, 786-794. [CrossRef]

13. Spiteri, K.; Broom, D.; Bekhet, A.H.; De Caro, J.X.; Laventure, B.; Grafton, K. Barriers and motivators of physical activity participation in middle-aged and older adults-A systematic review. J. Aging Phys. Act. 2019, 27, 929-944. [CrossRef]

14. WHO. Malta Physical Activity Fact Sheet 2018; World Health Organisation: Copenhagen, Denmark, 2018; pp. 1-4. Available online: http:/ / www.euro.who.int/_data/assets/pdf_file/0008/382571/malta-eng.pdf?ua=1 (accessed on 7 November 2019).

15. Behncke, S. Does retirement trigger ill health? Health Econ. 2012, 21, 282-300. [CrossRef]

16. Bennett, M.M.; Beehr, T.A.; Lepisto, L.R. A Longitudinal Study of Work After Retirement: Examining Predictors of Bridge Employment, Continued Career Employment, and Retirement. Int. J. Aging Hum. Dev. 2016, 83, 228-255. [CrossRef]

17. Chaudhury, M.; Shelton, N. Physical activity among 60-69-year-olds in England: Knowledge, perception, behaviour and risk factors. Ageing Soc. 2010, 30, 1343-1355. [CrossRef]

18. Hamer, M.; Kivimaki, M.; Steptoe, A. Longitudinal patterns in physical activity and sedentary behaviour from mid-life to early old age: A substudy of the Whitehall II cohort. J. Epidemiol. Community Health 2012, 66, 1110-1115. [CrossRef]

19. Hamer, M.; Lavoie, K.L.; Bacon, S.L. Taking up physical activity in later life and healthy ageing: The English longitudinal study of ageing. Br. J. Sports Med. 2014, 48, 239-243. [CrossRef]

20. Jokela, M.; Head, J.; Vahtera, J.; Westerlund, H.; Marmot, M.G. From midlife to early old age: Health trajectories associated with retirement. Epidemiology 2011, 21, 284-290. [CrossRef]

21. Bauman, A.E.; Reis, R.S.; Sallis, J.F.; Wells, J.C.; Loos, R.J.; Martin, B.W.; Lancet Physical Activity Series Working Group. Correlates of physical activity: Why are some people physically active and others not? Lancet 2012, 380, 258-271. [CrossRef]

22. Denton, F.T.; Spencer, B.G.; Denton, F.T.; Spencer, B.G. What Is Retirement? A Review and Assessment of Alternative Concepts and Measures. Can. J. Aging 2009, 28, 63-76. [CrossRef]

23. IPAQ Group. IPAQ. 2019. Available online: https://sites.google.com/site/theipaq/questionnaire_links (accessed on 14 November 2019).

24. Spiteri, K.; Grafton, K.; Xerri de Caro, J.; Broom, D. Translation of the International Physical Activity Questionnaire to Maltese and Reliability Testing. J. Meas. Phys. Behav. 2021, 4, 23-30. [CrossRef]

25. Kusano, K.; Kemmelmeier, M. Multi-level modelling of time-series cross-sectional data reveals the dynamic interaction between ecological threats and democratic development. R. Soc. Open Sci. 2020, 7, 25. [CrossRef] [PubMed]

26. DiPrete, T.; Grusky, D.B. The Multilevel Analysis of Trends with Repeated Cross-Sectional Data. Sociol. Methodol. 1990, 32, 337-368. [CrossRef]

27. Xanthakis, V.; Sullivan, L.M.; Vasan, R.S. Multilevel modeling versus cross-sectional analysis for assessing the longitudinal tracking of cardiovascular risk factors over time. Stat. Med. 2014, 32, 10. [CrossRef]

28. Government of Malta. 2021. Available online: https://deputyprimeminister.gov.mt/en/dhir/Pages/surveys.aspx (accessed on 2 August 2021).

29. Heck, R.H.; Thomas, S.L.; Tabata, L.N. Multilevel and Longitudinal Modeling with IBM SPSS, 2nd ed.; Routledge: London, UK, 2014.

30. Sun, F.; Norman, I.J.; While, A.E. Physical activity in older people: A systematic review. BMC Public Health 2013, 13, 449. [CrossRef]

31. Lahti, J.; Laaksonen, M.; Lahelma, E.; Rahkonen, O. Changes in leisure-time physical activity after transition to retirement: A follow-up study. Int. J. Behav. Nutr. Phys. Act. 2011, 8, 36. [CrossRef]

32. Smith, L.; Gardner, B.; Fisher, A.; Hamer, M. Patterns and correlates of physical activity behaviour over 10 years in older adults: Prospective analyses from the English Longitudinal Study of Ageing. BMJ Open 2015, 5, e007423. [CrossRef]

33. Lemelin, E.T.; Roux, A.V.; Franklin, T.G.; Carnethon, M.; Lutsey, P.L.; Ni, H.; O’Meara, E.; Shrager, S. Life-course socioeconomic positions and subclinical atherosclerosis in the multi-ethnic study of atherosclerosis. Soc. Sci. Med. 2009, 68, 444-451. [CrossRef] [PubMed]

34. Evenson, K.R.; Rosamond, W.D.; Cai, J.; Diez-Roux, A.V.; Brancati, F.L. Influence of retirement on leisure-time physical activity: The atherosclerosis risk in communities study. Am. J. Epidemiol. 2002, 155, 692-699. [CrossRef] [PubMed]

35. Touvier, M.; Bertrais, S.; Charreire, H.; Vergnaud, A.-C.; Hercberg, S.; Oppert, J.-M. Changes in leisure-time physical activity and sedentary behaviour at retirement: A prospective study in middle-aged French subjects. Int. J. Behav. Nutr. Phys. Act. 2010, 7, 14. [CrossRef]

36. Transport Malta. 3rd National Household Travel Survey 2010; Government of Malta: Valletta, Malta, 2010.

37. Changyong, F.E.; Hongyue, W.A.; Naiji, L.U.; Tian, C.H.; Hua, H.E.; Ying, L.U. Log-transformation and its implications for data analysis. Shanghai Arch. Psychiatry 2014, 26, 105-109.

38. Jackson, A.S.; Sui, X.; Hébert, J.R.; Church, T.S.; Blair, S.N. Role of lifestyle and aging on the longitudinal change in cardiorespiratory fitness. Arch. Intern. Med. 2009, 169, 1781-1787. [CrossRef] [PubMed]

39. Idler, E.; Cartwright, K. What Do We Rate When We Rate Our Health? Decomposing Age-related Contributions to Self-rated Health. J. Health Soc. Behav. 2018, 59, 74-93. [CrossRef]

40. Beyer, A.K.; Wolff, J.K.; Warner, L.M.; Schüz, B.; Wurm, S. The role of physical activity in the relationship between self-perceptions of ageing and self-rated health in older adults. Psychol Health 2015, 30, 671-685. [CrossRef]

41. Abuladze, L.; Kunder, N.; Lang, K.; Vaask, S. Associations between self-rated health and health behaviour among older adults in Estonia: A cross-sectional analysis. BMJ Open 2017, 7, e013257. [CrossRef] 
42. Yeung, D.Y.; Zhou, X. Planning for retirement: Longitudinal effect on retirement resources and post-retirement well-being. Front. Psychol. 2017, 8, 1300. [CrossRef]

43. Wang, M.; Henkens, K.; van Solinge, H. Retirement adjustment: A review of theoretical and empirical advancements. Am. Psychol. 2011, 66, 204-213. [CrossRef]

44. Cheng, H.G.; Phillips, M.R. Secondary analysis of existing data: Opportunities and implementation. Shanghai Arch. Psychiatry 2014, 26, 371-375.

45. Sattler, M.C.; Jaunig, J.; Tösch, C.; Watson, E.D.; Mokkink, L.B.; Dietz, P.; van Poppel, M.N. Current Evidence of Measurement Properties of Physical Activity Questionnaires for Older Adults: An Updated Systematic Review. Sports Med. 2020, 50, 1271-1315. [CrossRef]

46. Troiano, R.P.; Pettee Gabriel, K.K.; Welk, G.J.; Owen, N.; Sternfeld, B. Reported Physical Activity and Sedentary Behavior: Why Do You Ask? J. Phys. Act. Health 2012, 9, S68-S75. [CrossRef] [PubMed]

47. Loney, T.; Standage, M.; Thompson, D.; Sebire, S.J.; Cumming, S. Self-report vs. objectively assessed physical activity: Which is right for public health? J. Phys. Act. Health 2011, 8, 62-70. [CrossRef] [PubMed] 